\title{
Participação social em saúde em áreas rurais do Nordeste do Brasil
}

\author{
José Patrício Bispo Júnior ${ }^{1}$ e José Jackson Coelho Sampaio²
}

Como citar Bispo Júnior JP, Sampaio JJC. Participação social em saúde em áreas rurais do Nordeste do Brasil. Rev Panam Salud Publica. 2008:23(6):403-9.

RESUMO Objetivos. Analisar a participação social por meio dos Conselhos Municipais de Saúde (CMS) em dois municípios de pequeno porte do Nordeste do Brasil.

Métodos. Trata-se de um estudo exploratório, qualitativo, do tipo casos múltiplos, tendo como objeto de pesquisa os CMS de Lafayete Coutinho (Estado da Bahia) e Groaíras (Ceará). Os dados foram obtidos entre fevereiro e abril de 2005 por meio de análise documental, observação direta das reuniões dos CMS e entrevistas semi-estruturadas. Foram analisados decretos, leis e portarias municipais; relatórios anuais de gestão das secretarias municipais de saúde; planos municipais de saúde; e relatórios das conferências municipais de saúde. Também foram analisadas as atas dos conselhos desde a sua criação até o ano de 2004. Foram entrevistados 17 conselheiros de saúde, oito de Lafayete Coutinho e nove de Groaíras.

Resultados. Ambos os conselhos apresentaram irregularidades quanto à composição e à posse dos conselheiros, como a alta rotatividade de representantes e as constantes "reformulações" da composição do conselho. Além disso, o quadro dos CMS era totalmente renovado quando da posse de um novo prefeito. Também foram observadas irregularidades na freqüência das reuniões. Em Lafayete Coutinho, das 96 reuniões previstas foram realizadas 37; em Groaíras, das 186 reuniões previstas o CMS realizou 93. Na análise da atuação do CMS como formulador e controlador das politicas municipais de saúde, emergiram três categorias temáticas: estado de saúde da população e políticas públicas; organização e funcionamento dos serviços de saúde; e gestão financeira e prestação de contas. As entrevistas mostraram a insatisfação dos participantes com as práticas do CMS e a sua descrença quanto à representatividade e ao poder desses conselhos.

Conclusões. É preciso repensar as estratégias de participação social no Brasil a partir da perspectiva do desenvolvimento de práticas sociais de amadurecimento político e elevação da consciência cidadã.

Palavras-chave Participação comunitária, sistemas de saúde, população rural, Sistema Único de Saúde, Brasil.

1 Universidade Federal da Bahia (UFBA), Instituto Multidisciplinar de Saúde, Núcleo de Epidemiologia e Saúde Coletiva, Vitória da Conquista (BA), Brasil. Correspondência: Avenida Olívia Flores 3000, Candeias, CEP 45055-090, Vitória da Conquista, BA, Brasil. Fone: +55-77-3424.0102; e-mail: jpatricio@ufba.br

2 Universidade Estadual do Ceará (UECE), Centro de Ciências da Saúde, Fortaleza (CE), Brasil.
No decorrer das últimas décadas, a quase totalidade dos países tem discutido e implantado reformas em seus sistemas de saúde. No entanto, essas reformas não possuem propósitos comuns, nem tampouco seus idealizadores e defensores almejam alcançar os mesmos objetivos. Diferentes atores, orientados por distintos matizes ideo- lógicos, tentam conduzir os sistemas de saúde a diferentes conformações. Entretanto, esses diversos modelos de reforma têm apresentado uma característica em comum: a necessidade de criar espaços de participação dos cidadãos (1). O conceito de participação não é unívoco e tem se modificado em diferentes períodos e contextos (2). $\mathrm{Na}$ 
América Latina, diversos autores (2-5) apontam para a evolução do conceito de participação como mecanismo de redistribuição de poder na sociedade.

No Brasil, com a promulgação da constituição de 1988 (6), a participação da comunidade passou a ser um dos requisitos fundamentais para a implantação e a consolidação do Sistema Único de Saúde (SUS). Em 1990, foram publicadas as leis $8080 / 90$ (7) e 8142/ 90 (8) que institucionalizam e regulamentam a participação popular e o controle social na gestão da saúde, tendo como instâncias legalmente instituídas as conferências e os conselhos de saúde. Ainda do ponto de vista legal, em 2003, o Conselho Nacional de Saúde (CNS) publicou a Resolução 333/2003 (9), que institui parâmetros para a organização e a estruturação dos conselhos de saúde. Esses conselhos são de caráter permanente e deliberativo e sua função é atuar na definição de políticas públicas e no acompanhamento da gestão, tendo inclusive atribuições econômicas e financeiras $(8,9)$.

Os conselhos de saúde - fóruns legalmente instituídos de envolvimento da sociedade com o sistema de saúdeforam criados nos três níveis de governo, estadual, municipal e federal. Atualmente, existem mais de 5500 conselhos. A composição dos conselhos privilegia a participação comunitária. Possuem caráter paritário, em que a metade dos integrantes representa os usuários do sistema de saúde e a outra metade é destinada aos representantes de outras categorias, como profissionais de saúde e prestadores de serviços, inclusive gestores.

Todavia, a existência desse aparato legal não garante uma gestão democrática, nem a participação no SUS. Sobre os determinantes do processo participativo, Cortes (10) destaca como mais influentes a organização da população local e a disposição das autoridades em respeitar e incentivar as decisões coletivas. Alguns estudos $(11,12)$ têm demonstrado a dificuldade do exercício da participação social por debilidade nesses fatores. $\mathrm{O}$ pleno exercício da cidadania e a democratização do poder, por meio dos conselhos de saúde, serão sempre facilitados na presença de um território comprometido com a ampliação dos canais de participação (13).

No entanto, o clientelismo e o paternalismo ainda são características marcantes nas relações entre o governo e os grupos de interesse no Brasil, especialmente nas cidades pequenas e nas áreas rurais menos industrializadas do País. Embora os conselhos de saúde possam contribuir para a consolidação de formas mais democráticas na representação de interesses, eles têm seu o funcionamento limitado e condicionado pela realidade concreta das instâncias e da cultura política dos municípios brasileiros (10). Em muitos casos, o assistencialismo de algumas prefeituras aparece como uma das mais importantes e eficazes ferramentas para o processo de desmobilização social (12). O gestor de municípios pequenos pode tornar-se poderoso e opressor com o munícipe, pois o conhece pelo nome, família, religião, ideologia e partido político (13). Esse é um aspecto que merece especial atenção no Brasil em virtude do elevado número de municípios com população de até 10000 habitantes. Dos 5 507 municípios brasileiros, quase metade, 2727 (49,5\%), possui população inferior a 10000 habitantes, e $16 \%$ possuem menos de 5000 habitantes (14).

Frente a esse contexto, o presente artigo tem por objetivo analisar o exercício da participação social nos conselhos municipais de saúde (CMS) em dois municípios de pequeno porte do Nordeste do Brasil. Tais reflexões visam a contribuir para a efetivação da participação social e a consolidação do sistema de saúde brasileiro na perspectiva da construção de um SUS resolutivo, democrático, humanizado e participativo.

\section{MATERIAIS E MÉTODOS}

Trata-se de um estudo exploratório, de natureza qualitativa, do tipo casos múltiplos (15), para o qual foram escolhidos como objeto de pesquisa os CMS de Lafayete Coutinho (Estado da Bahia) e Groaíras (Estado do Ceará). Esses municípios possuem população inferior a 10000 habitantes, CMS em funcionamento e características sociodemográficas similares.
Lafayete Coutinho está localizado na região sudoeste da Bahia, distante $355 \mathrm{~km}$ da capital Salvador. Possui população de 4102 habitantes e taxa de urbanização de 46,83\%. O município de Groaíras, com população de 8741 habitantes e taxa de urbanização de $63,93 \%$, situa-se a $246 \mathrm{~km}$ de Fortaleza, capital do Ceará, e está localizado na região noroeste do estado (14). Ambos os municípios possuem economia pouco desenvolvida, centrada basicamente na atividade agropecuária de subsistência, sendo que a maior força das economias locais está relacionada aos empregos públicos, especialmente os de nível municipal, às aposentadorias e pensões e aos programas de transferência de renda do Governo Federal.

Os dados e informações foram obtidos por meio de análise documental, observação direta das reuniões do conselho e entrevistas semi-estruturadas. As informações obtidas em cada uma dessas fases foram analisadas em estágios múltiplos (16-18), de acordo com a natureza e as fontes de informação.

$\mathrm{Na}$ primeira fase, objetivou-se conhecer a estrutura e o funcionamento dos conselhos, bem como seu processo de evolução histórica. Em seguida, analisou-se a atuação e as deliberações proferidas, buscando-se conhecer o desempenho dos CMS e o seu poder de interferência sobre as políticas de saúde. Por fim, a terceira fase constou da análise dos discursos dos sujeitos, em que foram pesquisadas as informações relacionadas à representação do sentido coletivo e do processo de determinação das posições ocupadas.

A fase de campo foi realizada entre os meses de fevereiro e abril de 2005 . Os documentos analisados foram: decretos, leis e portarias municipais; relatórios anuais de gestão das secretarias municipais de saúde (SMS); planos municipais de saúde; e relatórios das conferências municipais de saúde. Além desses documentos, foram analisadas as atas dos conselhos desde a sua criação até o ano de 2004. Do CMS de Lafayete Coutinho foram analisados 8 anos de registros em ata, 1997 a 2004, e do CMS de Groaíras, 16 anos, 1989 a 2004, perfazendo um total de 24 anos de atas analisadas em todo o 
estudo. A seleção dos entrevistados fundamentou-se no protagonismo dos atores, identificados e selecionados de acordo com o conteúdo das atas e dos documentos analisados. Buscou-se incluir representantes dos diversos segmentos que compõem o conselho. A partir desses critérios, foram entrevistados 17 conselheiros de saúde, oito de Lafayete Coutinho (três prestadores e cinco usuários) e nove de Groaíras (quatro prestadores e cinco usuários).

Conforme regulamentação da Resolução 196/96 do Conselho Nacional de Saúde (19), o projeto da pesquisa que deu origem a este artigo foi analisado e aprovado pelo Comitê de Ética em Pesquisa da Universidade Estadual do Ceará.

\section{RESULTADOS}

\section{Composição e funcionamento dos conselhos}

Os CMS foram criados em períodos diferentes e com motivações também diferentes. O CMS de Lafayete Coutinho foi criado em junho de 1997 como requisito necessário ao processo de municipalização da saúde. O CMS de Groaíras foi criado em junho de 1989, anteriormente à criação do SUS e à promulgação da lei 8142/90. A institucionalização da participação social em Groaíras não surgiu como uma atitude imposta pela legislação, nem como exigência para a habilitação em determinado nível de gestão, mas sim por uma iniciativa conjunta do poder público local com a sociedade organizada, com o objetivo de envolver a população nos problemas de saúde.

Em ambos os casos, os conselhos apresentaram diversas irregularidades quanto à sua composição e à posse dos conselheiros, com destaque para a constante quebra da paridade entre os conselheiros usuários e os demais conselheiros, a alta rotatividade de representantes por parte de algumas entidades e as constantes "reformulações" da composição do conselho, realizadas, muitas vezes, de maneira informal e sem a devida alteração da legislação pertinente.
Outra característica é a coincidência entre os mandatos dos conselheiros e o tempo de gestão do poder executivo municipal. O quadro dos CMS era totalmente renovado quando da posse de um novo prefeito. Outra irregularidade observada nos dois municípios era o envolvimento direto de representantes políticos com os fóruns de participação popular. Em Lafayete Coutinho, o prefeito municipal foi empossado como conselheiro de saúde no ano de 1998. Em Groaíras, até o ano de 1994, dentre os representantes dos usuários, uma das vagas era destinada à câmara de vereadores.

Observou-se uma grande irregularidade na frequência das reuniões. Os conselhos não mantinham um calendário regular e, na maioria dos anos, o número de reuniões foi inferior ao preconizado. Em nenhum dos anos, os CMS reuniram-se, ordinariamente, uma vez por mês. Em Lafayete Coutinho, das 96 reuniões previstas para o período de 1997 a 2004, foram realizadas 37; em Groaíras, das 186 reuniões previstas para o período de 1989 a 2004, o CMS realizou apenas 93, correspondendo, respectivamente, a $38,5 \%$ e $50 \%$ das reuniões que deveriam ocorrer. Verificou-se, em muitas ocasiões, a dificuldade de estabelecimento do quorum mínimo para a reunião. As atas continham diversos apelos quanto à necessidade de maior empenho e dedicação dos conselheiros e proposições para o estabelecimento de mecanismos de punição aos conselheiros e às entidades faltosas.

\section{Atuação dos CMS e suas deliberações}

Na análise da atuação dos CMS frente ao papel de formulador e controlador das políticas municipais de saúde, emergiram três categorias temáticas: estado de saúde da população e políticas públicas; organização e funcionamento dos serviços de saúde; e gestão financeira e prestação de contas.

O estado de saúde da população foi objeto de constantes discussões nos conselhos. Assuntos relacionados ao abastecimento de água tratada e es- gotamento sanitário, combate às deficiências nutricionais, doenças reemergentes - especialmente dengue e cólera -, mortalidade infantil e gravidez na adolescência, estiveram sempre presentes na pauta de discussão. Sobre as políticas públicas de saúde, observou-se uma atuação limitada na aprovação de condições de gestão e na implementação de programas instituídos pelo Ministério da Saúde.

A organização e o funcionamento dos serviços de saúde foram os assuntos que mais ocuparam a pauta de discussão dos CMS. Os municípios estudados apresentaram problemas crônicos de deficiência da assistência à saúde e, em virtude disso, essas discussões tornaram-se perenes nos CMS. A debilidade na organização do sistema municipal de saúde, a dificuldade do acesso, os maus tratos aos usuários e a assistência farmacêutica foram objetos de constantes debates. Todavia, os conselhos pouco conseguiram influir sobre ações que desencadeassem a melhoria da assistência prestada à população. Embora os CMS constantemente deliberassem e cobrassem ação das SMS, os problemas relativos à assistência persistiam e sempre retornavam ao conselho.

A análise da gestão financeira e da prestação de contas mostrou que os conselhos não exerciam, de forma efetiva, uma ação fiscalizadora e de acompanhamento e controle dos recursos destinados à saúde do município. Os exercícios financeiros de muitos anos não foram avaliados pelo conselho, e mesmo nos períodos em que as contas foram aprovadas, esse processo ocorreu apenas para cumprir as exigências legais. As prestações de contas ocorriam de maneira superficial, com a apresentação de balancetes sucintos e aprovação imediata pelos conselheiros.

\section{O que dizem os atores}

A participação era entendida pelos conselheiros como instrumento de fiscalização da aplicação dos recursos financeiros e como instrumento para a melhoria da assistência à saúde. Foi observada uma supervalorização do 
envolvimento dos usuários, como se os determinantes da qualidade da assistência à saúde se reduzissem à participação de setores populares. Nesse sentido, a participação tem uma finalidade claramente definida e é vista como uma atividade meio para se atingir um melhor nível da assistência.

Foi uma chance pra nós melhorar um pouco a nossa saúde, eu acho que nada melhor que o conselheiro tá participando das reunião, fiscalizando como é que tá sendo aplicado o dinheiro da saúde, como é que tá funcionando o hospital, pra mim o conselho é isso. (Entrevistado 17, Groaíras).

Também emergem o desinteresse e a desmotivação da população com as questões coletivas. A falta de interesse dos usuários pela participação se relaciona à frustração da população pelo pouco poder de influência do conselho na condução do sistema de saúde. Também é destacado, em alguns discursos, o fato de a participação ser uma atividade voluntária e não proporcionar nenhum tipo de remuneração. É referida a utilização dos CMS apenas como espaço de homologação de decisões tomadas pelos gestores, o que desencadeia nos conselheiros sentimentos de impotência e conduz a reações de desinteresse e abandono dos espaços de participação.

No meu caso não, eu até deixei de participar pra evitar desgaste maior. Porque já vinha tudo pronto, antes da reunião começar a ata já estava pronta. (Entrevistado 07, Lafayete Coutinho)

Para os entrevistados, as prestações de contas eram apenas uma formalidade cujo objetivo era cumprir as determinações e os prazos legais. Foram relatadas irregularidades na condução do processo e pressões dirigidas aos conselheiros para a aprovação dos balancetes. Pôde-se observar ainda uma certa conivência e omissão em relação ao acompanhamento da gestão financeira, visto que, mesmo diante de irregularidades, as contas sempre eram aprovadas. Além disso, muitos foram os períodos em que as contas não foram apresentadas ou aprovadas pelo conselho.
Na hora da aprovação eles levavam a pasta pro conselho. Eles traziam os balancetes $e$ apresentavam no conselho, só pra gente ver, entendeu? Não era debatido com o tempo adequado. E às vezes é aquela coisa, aquela ata tinha que ser feita aquele dia para os conselheiros assinarem, para ir direto pro governo. Então às vezes não era analisado. (Entrevistado 06, Lafayete Coutinho)

A escolha dos conselheiros usuários ocorria de formas múltiplas, com predomínio de métodos não democráticos, por indicação da diretoria ou presidência da instituição. A escolha por eleição direta entre os membros da entidade era praticamente inexistente. A relação entre as entidades e os seus representantes apresentava-se de maneira frágil e informal. Não existiam espaços de discussão coletiva e definição da postura a ser defendida pelo representante. Os conselheiros, na maioria dos casos, atuavam de forma independente e individual.

Quando chegava a solicitação para a entidade, a entidade não tinha o bom senso de reunir todos que fazem parte daquela entidade pra escolher. Usar a democracia, sabe?! O presidente chega e diz: "você vai ser nosso representante no conselho de saúde". Tava escolhido. Sem discussão, sem eleição, sem nada. (Entrevistado 07, Lafayete Coutinho)

Muitos dos conselheiros estavam atuando só como representante de si mesmo. Porque eu nunca ouvi falar que um conselheiro depois da reunião, chegasse a repassar pra comunidade, numa reunião de bairro, reunir a associação de moradores, nunca tive conhecimento. Isso nunca aconteceu aqui na Groaíras. Lá ele assistia, lá ficava. Ele ia embora e pronto, acabou. Nem ele repassava, nem a comunidade cobrava dele, então ficava tudo como estava. (Entrevistado 09, Groaíras)

Os principais determinantes apontados como responsáveis pela atuação insatisfatória dos CMS foram o nível educacional dos representantes dos usuários, a existência dos policonselheiros, a dificuldade de transporte para os conselheiros residentes na zona rural e a interferência política local. Os conselheiros apontaram que a representação dos usuários é ocupada por segmentos de menor nível educa- cional, o que impedia a compreensão do discurso tecnicista e limitava a contra-argumentação com gestores e profissionais de saúde.

Eu gostaria muito se a gente pudesse colocar pessoas mais capacitadas, mais é muito difícil. Pessoas com conhecimentos maiores. Porque, geralmente, a gente de associação o conhecimento é pouco. Geralmente é pessoas de primeiro grau, é o cabra semi-analfabeto, e se tivesse a participação de pessoas mais qualificadas, mais estudadas, pessoas com um curso superior, seria muito melhor. Então, como não tem, tem que ser mesmo esse povão dando grito lá. (Entrevistado 17, Groaíras)

No que concerne ao interesse pela participação, os discursos revelam uma restrição a poucos cidadãos. $\mathrm{O}$ modelo de gestão adotado no Brasil, a partir da constituição de 1988, com forte ênfase na descentralização e na democratização, preconiza a criação de conselhos em vários setores da sociedade. Todavia, o processo de formação dos conselhos parece ter desencadeado uma particularidade inerente aos municípios de pequeno porte, a existência de policonselheiros, ou seja, cidadãos que participam de vários conselhos municipais.

Tem pessoas que acumulam muitas funções. (...) O que acontece é que acabava nas mãos das mesmas pessoas. O conselheiro de saúde também faz parte do conselho da criança, do fórum de usuários da água, de vários conselhos. São poucas as pessoas que querem participar, que querem ver a comunidade melhorar, então sempre eram as mesmas pessoas. (Entrevistado 06, Lafayete Coutinho)

A maioria dos entrevistados destacou a interferência dos processos políticos eleitorais locais como grande fator impeditivo para a plena participação da comunidade. Dentre os fatores políticos levantados, destacam-se o revanchismo político local e o envolvimento e cooptação de lideranças populares, com o intuito de inibir possíveis questionamentos e ações da categoria dos usuários.

Às vezes, também, a questão política, a política partidária. Porque se foi contra o pre- 
feito eles não participam. Alguns quando eram convidados a participar da reunião, falhavam, não compareciam, por que eram pessoas contra a administração. É porque eles pensam que estão prejudicando a quem tá no poder, estão prejudicando é a comunidade. Muitas pessoas, mais que a preocupação com a saúde do município estão preocupadas com a rixa política. (Entrevistado 03, Lafayete Coutinho)

Os entrevistados apontam a perniciosa interferência das disputas eleitorais locais no desenvolvimento das atividades dos conselhos, onde grupos e pessoas de orientação política oposta à administração municipal recusam-se participar das atividades dos conselhos. Esse processo de interferência política desencadeou sentimentos de impotência, revolta e desmotivação nos conselheiros.

\section{DISCUSSÃO}

Os municípios estudados, além de pertencer à mesma categoria populacional, possuem uma série de características socioeconômicas que evidenciam as adversas condições de vida de suas populações. Possuem nível educacional baixo, sendo em torno de um terço da população analfabeta. A taxa de mortalidade infantil é elevada, superior a 35 mortes para cada 1000 nascidos vivos. Além disso, a proporção de pobres é elevada, em torno de $70 \%$ (20). Essa áspera realidade condena esses municípios a sérios problemas de saúde de difícil resolução, especialmente se forem implementadas apenas políticas setoriais, com a manutenção da situação econômica vigente.

Apesar de os CMS terem sido criados em períodos diferentes, com intervalo de 8 anos entre a criação de cada um, e por motivações e circunstâncias também distintas, os problemas de funcionamento eram semelhantes. A presença de irregularidades no funcionamento do conselho também foi relatada por outros investigadores. Labra (21), ao sintetizar diversas experiências sobre o funcionamento dos conselhos de saúde, demonstrou as dificuldades referentes à composição desses conselhos e à constante quebra da paridade.

No que se refere à independência e à autonomia, os dois conselhos apresentam aspectos negativos, que evidenciam o atrelamento à gestão municipal. Nos dois casos, o tempo de posse dos conselheiros coincidia com o tempo de gestão do poder executivo municipal. Outra questão é a posse do prefeito municipal, em Lafayete Coutinho, e de vereadores, em Groaíras, como conselheiros de saúde. Tais situações, também observadas em outros conselhos (21), são uma afronta ao exercício do controle social, e tendem a enfraquecer as iniciativas de participação popular, visto que a presença de uma autoridade política no CMS pode inibir posicionamentos críticos, especialmente dos representantes dos usuários e dos profissionais de saúde.

A irregularidade na freqüência das reuniões é outra característica comum aos dois municípios. Esse fenômeno ocorre por dois motivos principais: a não convocação mensal das reuniões e a ausência dos conselheiros quando convocados. Esses motivos estão intimamente relacionados e demonstram o desinteresse dos gestores na promoção da participação popular e a desmobilização da população local. A não convocação regular de reuniões deveria ser motivo de contestação e mobilização dos representantes dos usuários. No entanto, em virtude da desmobilização social, percebe-se um efeito contrário de potencializar o desinteresse da população, o que leva a dificuldades de estabelecimento de quorum mínimo quando da convocação das reuniões. Esse processo de apatia e desmobilização pode ser indicativo de desequilíbrios que, em alguns casos, são o resultado de iniqüidades e, em outros casos, conduzem a elas (22). A baixa motivação para a participação pode estar escondendo um rechaço às práticas autoritárias locais, onde os afetados suportam passivamente uma realidade que não acreditam poder transformar (5).

Outra questão apontada como determinante no processo de desmobilização e desinteresse é a pouca capacidade de influência do conselho na condução das políticas de saúde. Em ambos os casos, os conselhos apresentavam-se apenas como homologadores das decisões previamente tomadas pelos gestores. Para agravar a situação, essas decisões, em sua maioria, apenas objetivavam atender as exigências legais das secretarias estaduais de saúde e do Ministério da Saúde. Esse processo potencializou os sentimentos de frustração e descrédito dos conselheiros, que não conseguiam influir nas decisões do conselho e não tinham força política para fazer implementar as decisões, mesmo aquelas induzidas pelo gestor.

Elias e Cohn (23) também citam limitações no poder de interferência dos conselhos. Isso se revela como ponto crítico nas propostas de participação, visto que as práticas e atitudes de auto-referência dos gestores têm desencadeado desmotivações e afastamentos entre os usuários (16). Outras pesquisas $(24,25)$ também demonstram insatisfação quanto à capacidade limitada de influência dos fóruns de participação popular e sentimentos de descrédito e abandono dessas instâncias.

O acompanhamento da gestão financeira é uma das principais fragilidades dos conselhos estudados. Embora a lei 8142/90 (8) e a resolução CNS 333/2003 (9) preconizem que o CMS deve acompanhar e fiscalizar regularmente o desempenho das atividades financeiras, os conselhos não conseguiam fiscalizar ou intervir sobre o orçamento da saúde. Deve ser destacada a estratégia adotada pelas SMS para aprovação das contas. As mesmas eram apresentadas na data limite para sua aprovação, acompanhadas da alegação de que a não aprovação desencadearia a suspensão de repasses financeiros para o município. Esse tipo de conduta expunha os conselheiros à situação conflitiva de enfrentar os possíveis prejuízos a que submeteriam o município, caso as contas fossem reprovadas, com a suspensão de repasse de recursos.

Outros estudos $(24,26)$ demonstraram dificuldades similares no acompanhamento e fiscalização do orçamento da saúde. Independentemente da maneira como as contas são apresentadas, observa-se uma atuação li- 
mitada dos conselhos, isto é, atuam apenas na fiscalização dos recursos que já foram utilizados, analisando os pagamentos já executados. Constatase, de maneira geral, uma dificuldade dos conselhos de opinar e interferir na alocação dos recursos, e de fazer cumprir tal alocação $(21,24,26)$.

Sobre a representatividade dos conselheiros, o predomínio de métodos não democráticos de escolha dos representantes e a fragilidade na mobilização política das entidades interferiram negativamente na atuação dos CMS. A questão da representatividade é debatida por Serapioni e Romaní (16), que afirmam não ser possível falar em representatividade na ausência de meios democráticos de escolha dos representantes. A fragilidade da relação entre representantes e suas bases demonstra a debilidade da organização social local $(11,27,28)$, que é apontada por Cortes (10) como um dos cinco fatores mais influentes do processo participativo.

A existência de policonselheiros surge como uma característica comum aos municípios de pequeno porte. Em virtude de sua pequena população e de o interesse pela participação estar restrito a um pequeno contingente de pessoas, alguns poucos cidadãos assumem a representação em vários conselhos. Essa situação é debatida por Labra (21) que aponta o predomínio das associações de moradores na representação dos usuários. Essas entidades, especialmente em municípios pequenos, são responsáveis por indicar representantes não somente para os CMS, mas, também, para os diversos conselhos de quase todas as áreas da atividade estatal, sobrecarregando os cidadãos de maior envolvimento no seio das associações.

A participação de apenas poucos cidadãos em quase todos os conselhos do município coloca duas questões que precisam ser debatidas e enfrentadas pela sociedade. Quais os motivos que levam ao desinteresse de grandes parcelas da população pela questão da participação? Quais as estratégias necessárias e adequadas para despertar um maior interesse da população pela participação? Essas são questões essenciais que precisam ser enfrentadas a fim de se potencializar os fóruns participativos, não só da área de saúde, mas nos diversos setores da sociedade.

No que tange à capacitação dos conselheiros, o nível educacional dos representantes aparece como determinante para o bom desempenho dos CMS. Destaca-se a dificuldade de envolvimento de pessoas com maior nível de instrução, especialmente com nível superior, na categoria dos usuários. $\mathrm{O}$ abandono por parte das elites intelectual e cultural dos fóruns de participação social e de construção coletiva das políticas públicas demonstra a desresponsabilização das elites em relação aos sistemas públicos, restando à população com menor nível de instrução, usuários do sistema, a responsabilidade pela sua defesa. Essa questão é percebida por Valla (29), que afirma que a participação popular no Brasil é entendida como envolvimento das classes populares e destinada aos grupos de baixo poder aquisitivo. Homedes e Ugalde (30) destacam que nas sociedades latino-americanas, estratificadas, as elites locais raramente utilizam o seu poder para resolver problemas comunitários.

O processo de interferência política aparece como um dos fatores de maior impedimento para a atuação plena do conselho. $\mathrm{O}$ enfraquecimento dos movimentos populares, a cooptação de lideranças e o revanchismo entre grupos oligárquicos rivais constituem-se como as principais estratégias de interferência política nos CMS. Essas práticas não ocorrem somente nos mu- nicípios estudados $(3,11,22)$. Os mecanismos de participação na área de saúde podem se constituir em mecanismos de legitimação do poder dominante e de cooptação dos movimentos sociais para a garantia da condição hegemônica local $(26,27,30)$. Outra questão comum é a utilização dos empregos públicos como instrumento de dominação e coerção, inibindo práticas de representação e mobilização popular $(10,22)$.

Embora os conselhos de saúde tenham possibilitado o envolvimento de um grande contingente de pessoas na defesa do SUS, situações como as descritas aqui tornam evidente a necessidade de se repensar o exercício do controle social no Brasil, a partir da perspectiva do desenvolvimento de práticas sociais de amadurecimento político e elevação da consciência cidadã.

Com base nos resultados deste estudo, apresentam-se algumas sugestões no intuito de contribuir para o fortalecimento do exercício da participação social na área de saúde, especialmente em áreas rurais. A capacitação dos conselheiros deve ocorrer de forma continuada, com a valorização da realidade local e o incentivo à coesão e à mobilização das entidades de representação popular. Devem ser pensados mecanismos de envolvimento de outros segmentos da sociedade, ainda omissos nas questões relacionadas ao SUS e à saúde coletiva. Por fim, sugerem-se iniciativas de sensibilização e capacitação de gestores, a fim de que a participação popular e os espaços de decisão coletiva possam ser melhor valorizados e respeitados.

Agradecimentos. À Fundação Cearense de Apoio ao Desenvolvimento Científico e Tecnológico (FUNCAP) pela bolsa concedida a José Patrício Bispo Júnior.

\section{REFERÊNCIAS}

1. Infante A, de la Mata I, López-Acuña D. Reforma de los sistemas de salud en América Latina y el Caribe: situación y tendencias. Rev Panam Salud Publica. 2000;8(1/2): 13-20.
2. Briceño-León R. El contexto político de la participación comunitaria en América Latina. Cad Saude Publica. 1998;14(Suppl 2):141-7.

3. Vázquez ML, Siqueira E, Kruze I, Silva A, Leite IC. Los processos de reforma y la parti- cipación en salud en América Latina. Gac Sanit. 2002;16(1):30-8.

4. Celedón C, Noé M. Reformas del sector de la salud y participación social. Rev Panam Salud Publica. 2000;8(1/2):99-104. 
5. Bronfman M, Carnevale $\mathrm{CH}$. Descentralización y participación en salud: nuevos aportes para la discusión. Em: Briceño-León R, Minayo MCS, Coimbra Jr. CEA, eds. Salud y equidad: una mirada desde las ciencias sociales. Rio de Janeiro: Fiocruz; 2000. Pp. 243-62.

6. Brasil. Constituição da República Federativa do Brasil. Brasília: Senado Federal; 1988. Disponível em: http://www.planalto.gov.br/ ccivil_03/Constituicao/Constitui\%C3\%A7ao. htm. Acessado em abril de 2008.

7. Brasil, Ministério da Saúde. Lei 8080/90. Diário Oficial da União. 19 de Setembro de 1990. Brasília; Ministério da Saúde; 1990. Disponível em: http://www.cff.org.br/Legisla\%C3\% A7\%C3\%A3o/Leis/lei_8080_90.html. Acessado em abril de 2008 .

8. Brasil, Secretaria da Saúde. Lei 8142/90. Brasília: Secretaria da Saúde; 1990. Disponível em: http://portal.saude.gov.br/portal/arquivos/ pdf/Lei8142.pdf. Acessado em abril de 2008.

9. Brasil, Ministério da Saúde, Conselho Nacional de Saúde. Resolução 333/03. Coletânea de Normas para o Controle Social no SUS. Brasília: Ministério da Saúde; 2006. Disponível em: http://conselho.saude.gov.br/biblioteca/ livros/coletanea_miolo.pdf. Acessado em abril de 2008.

10. Cortes SMV. Construindo a possibilidade de participação dos usuários: conselhos e conferências no Sistema Único de Saúde. Sociologias. 2002;4(7):18-49.

11. Atkinson S, Fernandes L, Caprara A, Gideon J. Prevention and promotion in decentralized rural health systems: a comparative study from northeast Brazil. Health Policy Plan. 2005;20(2):69-79.
12. Lima JC. Representatividade e participação das bases na categoria dos usuários de um Conselho Municipal de Saúde. Saude Debate. 2001;25(59):29-39.

13. Paim JS. Saúde política e reforma sanitária. Salvador: ISC/CEPS; 2002.

14. Instituto Brasileiro de Geografia e Estatística (IBGE). Censo Demográfico 2000. Rio de Janeiro: IBGE; 2001. Disponível em: http:/ /www. ibge.gov.br/home/estatistica/populacao/ censo2000/default.shtm. Acessado em abril de 2008.

15. Yin RK. Estudo de caso: planejamento e métodos. $2^{\mathrm{a}}$ ed. Porto Alegre: Artmed; 1994.

16. Serapioni M, Romaní O. Potencialidades e desafios da participação em instâncias colegiadas dos sistemas de saúde: os casos de Itália, Inglaterra e Brasil. Cad Saude Publica. 2006; 22(11):2411-21.

17. Minayo MCS. O desafio do conhecimento: pesquisa qualitativa em saúde. $8^{\mathrm{a}}$ ed. São Paulo: Hucitec; 2004.

18. Strauss A, Corbin J. Basics of qualitative research. Newbury Park: Aldine; 1990.

19. Brasil, Conselho Nacional de Saúde. Resolução 196/96. Critérios sobre pesquisas envolvendo seres humanos. Bioética. 1996;4(2): $15-25$.

20. Instituto de Pesquisa Econômica e Aplicada. Atlas de Desenvolvimento Humano do Brasil. Brasília: IPEA; 2003.

21. Labra ME. Conselhos de saúde: dilemas, avanços e desafios. Em: Lima NT, Gerschman S, Edler FC, Suaréz JM, org. Saúde e democracia: história e perspectivas do SUS. Rio de Janeiro: Fiocruz; 2005. Pp. 353-83.

22. Ramos GS. Participación social en el campo de la salud. Rev Cubana Salud Publica. 2004;
30(3). Disponível em: http://scielo.sld.cu/ $\mathrm{pdf} / \mathrm{rcsp} / \mathrm{v} 30 \mathrm{n} 3 / \mathrm{spu} 05304 . \mathrm{pdf}$. Acessado em abril de 2008.

23. Elias PE, Cohn A. Health reform in Brazil: lessons to consider. Am J Public Health. 2003; 93(1):44-8.

24. Gonçalves ML, Almeida MCP. Construindo o controle social e a cidadania em uma experiência concreta: o Conselho Municipal de Saúde de Ribeirão Preto. Saude Debate. 2002; 26(61):167-75.

25. Bosi MLM, Affonso KC. Cidadania, participação popular e saúde: com a palavra, os usuários da rede pública de serviços. Cad Saude Publica. 1998;14(2):355-65.

26. Correia MVC. Que Controle social? Os conselhos de saúde como instrumento. Rio de Janeiro: Fiocruz; 2000.

27. Bettiol LM. Saúde e participação popular: o programa de saúde da família. São Paulo: UNESP; 2006.

28. Jewkes R, Murcott A. Community representatives: representing the "community"? Soc Sci Med. 1998;46(7):843-58.

29. Valla VV. Sobre a participação popular: uma questão perspectiva. Cad Saude Publica. 1998;14(suppl 2):7-18.

30. Homedes N, Ugalde A. Las reformas de salud neoliberales en América Latina: una visión crítica a través de dos estudios de caso. Rev Panam Salud Publica. 2005;17(03):210-20.

Manuscrito recebido em 30 de julho de 2007. Aceito em versão revisada em 6 de fevereiro de 2008

ABSTRACT Objectives. To analyze the social participation taking place through Municipal Health Councils (MHC) in two small towns in northeastern Brazil.

\section{Social participation in health in rural northeastern Brazil}

Methods. A qualitative, exploratory, multicase study focused on the MHCs of Lafayete Coutinho (state of Bahia) and Groaíras (state of Ceará) was conducted. Data were gathered from February-April 2005 through analysis of documents, direct observation of MHC meetings, and semistructured interviews. Documents analyzed included decrees, laws, and municipal regulations; city health department annual management reports; municipal health plans; and reports of municipal health conferences. MHC meeting minutes for the period between inception of these councils and 2004 were also reviewed. Interviews of 17 council members took place, eight of whom were from Lafayete Coutinho and nine from Groaíras.

Results. Both councils had irregular practices regarding membership structure and nomination of members, such as frequent changes in appointed members and continuous "reshuffling" of council structure. In addition, new council members were appointed each time a new mayor took charge. Sporadic frequency of meetings was also observed. In Lafayete Coutinho, of 96 meetings planned, just 37 took place; in Groaíras, of 186 meetings planned, 93 took place. Analysis of MHC efforts to formulate and control municipal health policies revealed three themes: health status of the population and public policies; organization and functioning of health services; and financial management and accounting. The interviews showed that council members were dissatisfied with the practices of the MHCs and revealed a lack of confidence in how truly representative the councils are and how much power they have.

Conclusions. Social participation strategies in Brazil must be reconsidered with an angle toward promoting political responsibility and raising awareness among citizens.

Key words Community participation, health policy, rural population, Single Health System, Brazil. 